\title{
The role of social media in managing supplier attractiveness:
}

\author{
An investigation of business-to-business markets
}

\begin{abstract}
Purpose - Managing attractiveness is a constant challenge to mobilize relationship-specific investments, especially in a business environment increasingly enhanced by social media activities. There is limited knowledge on how social media activities contribute to supplier attractiveness, so decisions about strategizing with social media and consequent resource allocations become highly uncertain. The purpose of this study is to examine how suppliers' social media activities influence supplier attractiveness.
\end{abstract}

Design/methodology/approach - Altogether, 57 senior managers were interviewed: 32 semistructured in-depth interviews were conducted with senior managers in strategic decisionmaking roles regarding social media on the supplier side, along with 20 senior managers responsible for purchasing or looking after supplier development; one-to-one interviews were complemented by a focus group with 5 senior managers on the buyer side.

Findings - The study reveals a U-shaped relationship between the intensity of the supplier's social media activity and its attractiveness and offers a set of propositions about the influence of social media on supplier attractiveness, with special regard to the perceived risks of increased transparency and becoming 'too social' on social media.

Practical implications - The study highlights social media management results for supplier attractiveness and their impact areas on business growth and supply chain development.

Originality/value - This paper provides in-depth insights into the role of social media in managing supplier attractiveness. Various effects of social media activities are identified that aim to contribute to the body of literature on supplier attractiveness as well as social media management in buyer-supplier relationships.

Keywords: social media, supplier attractiveness, supplier selection, buyer-supplier relationships 


\section{Using social media to increase supplier attractiveness:}

\section{An investigation of business-to-business markets}

\section{Introduction}

Suppliers delivering to business markets are under increasing pressure to catch up with the considerably more sophisticated Social Media (SM) management practices of their Businessto-Consumer (B2C) counterparts (McKinsey, 2016). Although several SM platforms were designed with individual users in mind, SM has been widely applied in Business-to-Business (B2B) contexts, including operations and supply chain management (Lam et al., 2016). It is acknowledged that SM influences inter-organizational decision-making processes (Sashi, 2012; Rapp et al., 2013; Cui et al., 2018) and that buyer-supplier dynamics differ considerably from consumer interaction (Trainor et al., 2014). However, researchers have paid considerably less attention to addressing the role of SM in buyer-supplier relationships, one critical issue of which is the management of supplier attractiveness. In particular, there is a scarcity of guidance on whether suppliers should just follow B2C SM approaches or whether they should go their own way in managing SM to improve their attractiveness. This is vital for resource allocation purposes, as well as for the efficient management of buyer-supplier relationships in a digitallyenhanced business environment.

Attractiveness in buyer-supplier relationships matters because it helps to mobilize relationshipspecific investments such as time, the allocation of skilled employees, and financial investments (Bemelmans et al., 2015). Transforming organizational practices in an increasingly digitally-enhanced business environment - including SM - to manage supplier attractiveness is a challenge to both researchers and practitioners, addressed by a few notable contributions: for instance, Aral et al. (2013) called for more research on how SM affects relationship formation and the development of relationships. A significant gap is that research on the effects of SM on organizational attractiveness remains fragmented and discursive (for example, Bollen et al. (2011) addressed some issues relevant to attractiveness in a stock market context and Luo et al., (2013) conducted research specific to firm equity value), with no research addressing supplier attractiveness in the light of SM, and so a clear and inclusive research agenda has yet to be established in this regard. Despite its practical relevance, the current scarcity of research on supplier attractiveness and SM is inevitably a barrier to the strategizing of SM use in buyer-supplier contexts. This paper aims to develop a more 
comprehensive understanding of the role of SM in managing supplier attractiveness. Thus, the study offers contributions to the literature on organizational attractiveness, and to the discussions on the role of SM in buyer-supplier relationships and how SM can help to build competitive advantage through enhancing attractiveness.

We address the gap of how SM influences supplier attractiveness by synthesizing relevant knowledge in the domains of supplier attractiveness and SM management. Our research focused on the relational impact of SM and was guided by the Research Question (RQ), "How do SM activities of the supplier influence the supplier's attractiveness?”. The analysis of rich qualitative data enabled the revealing of SM implications relevant to the drivers of attractiveness and how supplier attractiveness can be enhanced by SM presence. 57 senior managers with relevant experience were interviewed both on the supplier and buyer side: 32 semi-structured, in-depth interviews were conducted with senior managers in strategic decision-making roles regarding SM on the supplier side, along with 20 senior managers responsible for purchasing or looking after supplier development; one-to-one interviews were complemented by a focus group with 5 senior managers on the buyer side. Studying managerial experiences helped to explore how the supplier's attractiveness is managed in order to appeal to buyers, as well as buyer's perception of the supplier's attractiveness with special regard to SM interactions.

The paper is structured in the following way: Section 2 reviews the literature on supplier attractiveness and its enhancement through SM employment. Section 3 explains the methodology of the empirical study. Section 4 provides the analysis and findings on the supplier and buyer sides as well as their comparison. Finally, in Section 5, discussion and managerial implications are examined. In the discussion, we offer a set of propositions based on the findings for further research.

\section{Literature}

\subsection{Supplier attractiveness in digitalized environments}

Supplier attractiveness refers to the appeal of the supplier as perceived by the buyer, which acts like a magnetic force that pulls the buyer towards the supplier in a dyadic relationship based on the qualities the supplier possesses (Ellegaard \& Ritter, 2007). Makkonen et al. (2016) demonstrate that both the buyer's and supplier's perspectives have an impact on attractiveness outcomes due to the interactional nature of relationship development. Major factors in choosing 
to focus on supplier attractiveness were that it is the fundamental reason for the buyer to pursue interaction with a supplier (Gosling et al., 2010); it is a key determinant of successful buyersupplier relationships (Olsen and Ellram, 1997), and it is relevant for supplier portfolio management - for example, as a segmentation criterion (Osiro et al., 2014), and as a strategic planning tool for future purchasing portfolios (Luzzini et al., 2012). As part of their portfolio strategy, buyers need to evaluate the attractiveness of suppliers, and prioritize the allocation of resources accordingly (Luzzini et al., 2012). Managing the firm's attractiveness can be regarded as an addition to direct sales given its less straightforward and more holistic nature compared to sales (Fiocca, 1982). For the purpose of our research, supplier attractiveness was defined as the attitude towards the partner firm, which incorporates previous experiences and future expectations with them; attractiveness incentivizes the focal firm to build a new relationship or to maintain an existing relationship by making relationship-specific investments (Tóth et al., 2015). We chose this definition as it was aligned with the social dynamics of SM usage (Levina \& Arriaga, 2014), therefore both the past experiences and the emergent, futureoriented aspects of attractiveness are encapsulated in it.

In a digitally-enhanced business environment, SM constitutes an integral part of the supplier's online presence (Rapp et al., 2013), and in turn impacts its attractiveness towards buyers and other partners. The study applies the SM definition of Kaplan and Haenlein (2010), i.e. that SM constitutes various Internet-based applications that instead of one-way information sharing, allow for content generation and sharing by users, where content can be continuously modified in a collaborative fashion. Content may include written messages, as well as pictures, videos, animation, audio-materials, and web links to external sites, each establishing the interface for interactions relevant to the development of buyer-supplier relationships. Such an inclusive definition of SM allows the inclusion of any SM platform that appears relevant in the studied buyer-seller relationships.

While a plethora of research addresses attractiveness in different settings, an important common thread is that achieving attractiveness requires more than the obvious financial benefits (Ellegaard \& Ritter, 2007; Hald et al., 2009; Tanskanen \& Aminoff, 2015). The drivers of supplier attractiveness are linked to economic factors, financial performance, and technological factors, as well as organizational, cultural, and strategic factors (Olsen \& Ellram, 1997). Hald et al. (2009) examine the similarities and differences between supplier and buyer attractiveness: the authors consider expected value, trust, and dependence from the perspective 
of both partners as relevant. With regard to supplier attractiveness, cost reduction, timely delivery, and innovation potential appear important, while for the buyer's attractiveness the agreed price, purchasing volume, and growth potential are reported as priorities.

Financial rewards (Olsen \& Ellram, 1997) are highly relevant for attractiveness, and are normally based on the financial records of the firm and economic evaluation concerning the stability and expected margins. Non-financial rewards, including reputational or networkrelated benefits (Mortensen, 2012; Aminoff \& Tanskanen, 2013) are also widely considered. Non-financial benefits typically include reputational benefits, knowledge sharing, and network-related benefits (Leonardi, 2014). Furthermore, cost considerations are important, including switching costs, wasted time, or potentially negative reputational impact whilst dealing with difficult suppliers (Sharma \& Patterson, 2000). Trust - both inter-organizational and inter-personal trust - is among the drivers of attractiveness (Cropranzano \& Mitchell, 2005). A good balance needs to be achieved between different perceived rewards and costs in order for the supplier to become attractive. It is noteworthy that small firms often face significant barriers regarding resources and skills when seeking improvements - and improving online presence is no exception - while larger firms tend to have more ample resources and decision-making structures in place (Matthews et al., 2017). Nevertheless, the strategic uncertainty is still present on how to best allocate the available resources and how SM can contribute to the firm's higher-level strategies.

\subsection{Supplier attractiveness and competitive advantage}

Attractiveness contributes to the firm's competitive advantage because it fosters relationshipspecific investments, including financial investments such as purchase and financial contributions to joint innovation efforts, but can also incorporate 'in kind' investments such as time, attention, allocation of skilled labor, and knowledge-sharing (Zhao \& Wang, 2011). Supplier attractiveness plays a role in the buyer's actions and adaptations regarding the relationship (Makkonen et al., 2016). Thus, any supplier that wishes to seek new buyers or deepen its relationships with existing customer firms needs to strategically consider how it can improve its attractiveness.

Competitive advantage is about offering buyers more value than competitors in either the whole market or a market niche, which may be in the form of offering lower prices for equivalent benefits (i.e. competing on cost), or offering unique benefits at premium prices (i.e. competing 
on differentiation) (Porter, 1985). While cost is a rather objective measure, differentiation could be based on actual or perception-based features and characteristics of the offering, such as product packaging, distribution, and prestige value of a brand name (e.g. Dickson \& Ginter, 1987). To successfully pursue a strategy for competitive advantage, companies need to exploit their strengths and weaknesses, whilst actively responding to opportunities and threats emanating from the micro (competitive) and macro environment in which they are embedded. In that respect, competitive advantage is only realized when the value offering strategy is not being offered by current or potential competitors - its sustainability relies on the resilience of the benefits (cost or differentiation) to be duplicated by competitors (Barney, 1991). Given that the supplier needs to stand out from the competition to appeal to the buyer and sustain this position, attractiveness can be regarded as a proxy of competitive advantage, especially when the basis of competitive advantage is differentiation.

In terms of considering opportunities for differentiation, it is important to mention that the firm resources are often socially complex. Socially complex firm resources, such as interpersonal relations between managers and the firm's reputation among buyers and suppliers are imperfectly imitable, hence can serve as sources of sustained competitive advantage (Barney, 1991). SM increases the social complexity of firm resources - in fact, Malhotra et al. (2013) posit SM as an enabler of creating and leveraging strategic differentiation capabilities. It is noteworthy to mention that the differentiation potential of SM does not primarily stem from the technical specificities of SM platforms: past research has assessed technology, including complex information management systems, as typically imitable, since any company could purchase such technology (Barney, 1991). Indeed, embarking on the use of a new SM platform, under some conditions, is readily imitable. Thus, the social-relational embeddedness of SM, its potential to reconfigure established social structures and knowledge flows (Leonardi, 2007), are more relevant for this study than the technical side of SM. This is underlined by Lam et al. (2016), who emphasized that SM strengthens the information flow across traditional organizational structures that promotes the formation of powerful information-sharing channels and advice-seeking networks.

\subsection{Mechanisms through which social media affects supplier attractiveness}

Although the current understanding of the impact of SM activities on supplier attractiveness is limited, it has been shown that SM can have a positive effect on managing various attractiveness-related issues in $\mathrm{B} 2 \mathrm{~B}$ - especially through relational mechanisms (Trainor et al., 
2014). SM improves the efficiency of interactions (Lam et al., 2016), for example, by reducing response time. Besides, compared to other communication tools, SM is still considered relatively cost efficient (Kaplan \& Haenlein, 2010), which is especially important for smalland medium-sized firms.

SM mechanisms such as rating, liking, up-voting/down-voting, commenting, sharing, and updating news feed all contribute to enabling faster information flow and better knowledge sharing that, according to Lam et al. (2016), result in operational efficiency improvements. Kauremaa et al. (2009) highlight that operational efficiency improvements create a positive relational impact, especially from the buyer's perspective. Ollus et al. (2011) suggest that organizations should use SM to enable collaborative project management efforts, in which trust is one of the most important factors. Thus, the adoption of SM can enhance mutual trust (Agnihotri et al., 2016).

Reputational mechanisms are relevant as well: a recent study by Mani and Gunasekaran (2018) suggests that issues within the supply chain can be revealed through SM interactions, which influence the firm's reputation. Reputation is among the drivers of attractiveness (Zarrinpoor, 2018). Overall, improving operational efficiency, reputation, and trust within buyer-seller relationships can indeed improve perceived attractiveness (Ramsay et al., 2013). Relevant changes triggered by SM activities can spread beyond the boundaries of the buyer-seller dyad and often apply to a wider network context: Aral et al. (2013) envision major implications on demand, competition, and firm strategy at a large scale.

\subsection{External factors affecting how social media affects supplier attractiveness}

Connecting external factors with internal mechanisms, SM presents an important capacity to display relevant information to buyers and a wide group of stakeholders that helps to overcome geographical boundaries (Lam et al., 2016). An overall increased understanding of environmental factors such as supply and demand through SM supports the effectiveness of innovation efforts (Chae, 2015), and thus improving innovativeness can increase attractiveness (Azadegan \& Dooley, 2010). Besides information sharing, SM can be utilized for creating a relevant market knowledge base for product and service innovation purposes both at the frontend (initial information gathering about buyers' needs) and the back-end (collecting feedback on solutions for fine-tuning before launch) of the innovation process (Roberts \& Piller, 2016). 
Environmental turbulence, including technological and market turbulence, can push or hinder firms from investing time and effort into managing SM, as demonstrated by Guo et al. (2018) in a Chinese context. The level of technological turbulence appears relevant for the adaptation of various SM platforms, while market turbulence may influence the relational complexity pertaining to interactions facilitated by SM. As for other technologies, integrating and managing SM in well-established organizations requires to some extent different approaches compared to new entrants (Karlsson et al., 2010).

While external factors such as business climate and network structures can affect SM usage, SM in return can increase connectivity in networks (Quinton \& Wilson, 2016), partly through generating Word-of-Mouth (Michaelidou et al., 2011). The maturity of buyer-seller relationships can be considered as another external factor but the time perspective of the relevance of SM is not restricted to a specific relationship stage; in fact, SM interactions remain influential across different stages of buyer-supplier relationships, from attracting new buyers (Michaelidou et al., 2011) to nurturing existing relationships (Lacoste, 2016). Companies can use professional SM platforms as information sources to find new collaborative relationships to develop innovation that leads to improved financial performance (Mitrega et al., 2017).

\section{Methodology}

Considering the exploratory nature of the study and the research question on how SM activities of the supplier influence the supplier's attractiveness, a case study methodology drawing on qualitative data was selected. Case studies are appropriate for exploratory investigations, where a more in-depth understanding on the phenomena of interest is required (Voss et al., 2002), and researchers are seeking to find answers for 'how?' and 'why?' questions (Yin, 2009). An abductive approach, systematic combining, (Dubois \& Gadde, 2002) was applied, and the initial theoretical underpinnings of the study were further developed through matching the empirical evidence to relevant literature. In order to capture potentially different patterns pertaining to attractiveness and to deepen contextual understanding (Yin, 2009), multiple firms both on the buyer and the supplier side were approached. Another reason why a multiple-case study approach was chosen in comparison to a single-case study is that multiple-case studies are normally considered more robust (Yin, 2009). For the data collection phase, a two-step sampling procedure was implemented by first using firmographics (i.e. type of industry and firm size), and secondly, identifying key informants within the chosen firms (i.e. based on relevant experience, influence, and position). In applying these sampling criteria, we followed 
a common practice for the study of buyer-supplier relationships (e.g. Cheng \& Musaphir, 1996; Thomas-Seale et al., 2018). We then identified buyers of the selected organizations and followed the same sampling procedures.

\subsection{Selection of companies}

Companies were identified from a university network with the help of a market research firm that works closely with the university in the extended Shanghai area in China. Shanghai and its surroundings make for one of the top industrial regions globally (Ma et al., 2013), which is highly relevant for the study of buyer-supplier relationships. All companies included in this phase were medium to large size. The exclusion of small firms was driven by the assumption that larger firms would have the means to manage SM and to carry out professional evaluations (Matthews et al., 2017). In the pursuit of clarity, small firms and medium to large ones were distinguished based on the number of employees, assuming employee numbers below 100 for small firms (Alfaro \& Tribó, 2003). The smallest firm had 150 employees; i.e. small firms were not included.

The first phase of the study focused on selecting companies that would serve as the suppliers in the dyadic relationships. Therefore, Original Equipment Manufacturers (OEMs) that put strategic priority on buyer-supplier relationships were included in the study. A range of manufacturing industries was represented (Table 1), namely the water pump industry, office furniture manufacturing, security systems, electric power generation, propulsion systems, automobile, semiconductors, electric vehicles, elevator manufacturing, and construction industries.

The second phase in the research involved collecting data from the buyers in the dyadic relationships under investigation. The selected companies had established supplier-buyer relationships with the OEMs involved in the first phase of our study. This additional phase in data collection and analysis provided further interesting insights, which allowed us to capture the true relational context of attractiveness: from the buyers, valuable insights were gained on how they perceive SM influence on the suppliers' attractiveness. This complements the information gained from the suppliers on how they manage attractiveness and their relevant experiences. Altogether, 10 buyer firms were interviewed with two senior managers per company, allowing us to study 10 buyer-supplier pairs in total. The remaining six suppliers did not provide information about their buyers or their buyers were not available to be interviewed. 
Industries included industrial electrical equipment, medical equipment, and automotive and telecommunication industries (Table 1).

\subsection{Data collection approach}

The study aimed to explore supplier attractiveness in a geographical context in which SM is sufficiently developed. There are more than 300 million SM users in China (Zhou \& Wang, 2014), with the SM registration rate of Chinese urban residents in excess of 95\%, with a dynamic increase in the registration of businesses (McKinsey, 2012). China has become the largest SM network globally (Chen, 2012). Various types of SM platforms are used in China, e.g. Weibo (similar to Twitter), WeChat (similar to Facebook and WhatsApp), and Zhihu (similar to Quora). It was decided that China would offer the right environment for our exploratory research that aimed to develop understanding about how suppliers manage their attractiveness to appeal to their buyers.

The ethical guidelines of a major UK university were followed to ensure ethical data management practices and that the identities of the managers and firms remain confidential. To enhance data triangulation, two managers were interviewed per company. Gaining multiple perspectives for each firm was important for consistency between managerial descriptions. While phase one focused on the supplier's perspective and phase two on the buyer's perspective, it is noteworthy that phase two was initially facilitated by a focus group, which allowed the collection of tentative evidence for the perception of supplier attractiveness from the perspective of the buyer. Subsequently, we incorporated data from 20 additional in-depth interviews with managers who are involved in the decision-making process regarding supplier selection in various senior positions at their firms.

Initial guidelines for the interview protocol for phase one were formulated drawing on the literature review presented in this study, as well as on input from two qualifying managers (not included in Table 1 as these preparations can be considered as pre-test) to ensure conceptual clarity and a logical flow of question blocks. The focus group also contributed to the finetuning of the interview protocol to ensure appropriateness for the one-to-one in-depth interview data collection in phase two.

Managers were initially approached within the selected companies via email. On the supplier side, interviewees' senior managerial roles and prior experiences enabled them to have substantial understanding of their companies' SM management and B2B strategies. Data was 
collected from these professionals because of their strategic role, influence, and first-hand experiences specific to their organizations and their interaction with buyers. On the buyer side, interviewees had relevant experiences in selecting and managing suppliers and were thus directly involved in the evaluation of supplier attractiveness. All one-to-one interviews were semi-structured with an average duration of one hour with the suppliers and around 70 minutes with the buyers. All interviews were audio-recorded and transcribed with the help of professional transcription services that resulted in a total of 324 pages of transcripts.

\begin{tabular}{|c|c|c|c|c|c|c|c|c|c|}
\hline Co. & M. & Position & Industry & Emp. & Co. & M. & Position & Industry & Emp. \\
\hline \multirow{2}{*}{ S1 } & M1 & Senior marketing manager & \multirow{2}{*}{$\begin{array}{l}\text { Water-pump } \\
\text { industry }\end{array}$} & \multirow{2}{*}{500} & & & & & \\
\hline & M2 & Account director & & & & & & & \\
\hline \multirow{2}{*}{ S2 } & M1 & Vice-president & \multirow{2}{*}{$\begin{array}{l}\text { Office furniture } \\
\text { industry }\end{array}$} & \multirow{2}{*}{300} & \multirow[t]{2}{*}{ B6 } & Ml & Supply chain manager & \multirow{2}{*}{$\begin{array}{l}\text { Electrical } \\
\text { engineering }\end{array}$} & \multirow[t]{2}{*}{35000} \\
\hline & M2 & Senior marketing manager & & & & M2 & Procurement manager & & \\
\hline \multirow{2}{*}{ S3 } & M1 & Vice-president & \multirow{2}{*}{ Security industry } & \multirow{2}{*}{800} & & & & & \\
\hline & M2 & Marketing director & & & & & & & \\
\hline \multirow{2}{*}{ S4 } & M1 & Vice-president & \multirow{2}{*}{ Power industry } & \multirow{2}{*}{150} & & & & & \\
\hline & M2 & Sales director & & & & & & & \\
\hline \multirow{2}{*}{ S5 } & M1 & Marketing director & \multirow{2}{*}{$\begin{array}{l}\text { Kitchen \& bath } \\
\text { industry }\end{array}$} & \multirow{2}{*}{2000} & \multirow[t]{2}{*}{ B5 } & M1 & Operations manager & \multirow{2}{*}{$\begin{array}{l}\text { Furniture } \\
\text { industry }\end{array}$} & \multirow[t]{2}{*}{2000} \\
\hline & M2 & E-commerce director & & & & M2 & Procurement manager & & \\
\hline \multirow[b]{2}{*}{ S6 } & M1 & Marketing director & \multirow{2}{*}{$\begin{array}{l}\text { Propulsion } \\
\text { systems for } \\
\text { vehicles }\end{array}$} & \multirow[b]{2}{*}{1300} & \multirow[t]{2}{*}{ B4 } & M1 & Supply chain manager & \multirow{2}{*}{$\begin{array}{l}\text { Automotive } \\
\text { industry }\end{array}$} & \multirow[t]{2}{*}{2000} \\
\hline & M2 & $\mathrm{PR}$ director & & & & M2 & Procurement manager & & \\
\hline \multirow{2}{*}{ S7 } & M1 & Marketing director & Automobile & 12000 & & & & & \\
\hline & M2 & Customer director & industry & 12000 & & & & & \\
\hline S8 & M1 & Marketing director & Semiconductor & 3000 & & & & & \\
\hline 38 & M2 & PR director & Semiconauctor & 3000 & & & & & \\
\hline S9 & M1 & Marketing director & Flectric vehicle & 1600 & & & & & \\
\hline & M2 & Vice-president & Electric ventere & 1000 & & & & & \\
\hline & M1 & Marketing director & & & B2 & M1 & Procurement manager & Industrial & 2000 \\
\hline S10 & M2 & PR director & $\begin{array}{l}\text { Security products } \\
\& \text { solutions }\end{array}$ & 34000 & & M2 & Operation manager & $\begin{array}{l}\text { electrical } \\
\text { equipment } \\
\text { industry }\end{array}$ & \\
\hline S11 & M1 & Customer director & Elevator & & B8 & M1 & Operation manager & Construction & 1000 \\
\hline S11 & M2 & Marketing director & manufacturer & 2000 & & M2 & Procurement manager & industry & \\
\hline S12 & M1 & Marketing director & Furniture & 500 & B7 & M1 & Procurement manager & Real estate & 500 \\
\hline 312 & M2 & Senior channel manager & manufacturing & 500 & & M2 & Operation manager & industry & \\
\hline & Ml & Marketing director & & & B9 & M1 & Procurement manager & Telecommuni & 1500 \\
\hline S13 & M2 & Customer director & manufacturers & 1000 & & M2 & Supply chain manager & $\begin{array}{l}\text { cations } \\
\text { industry }\end{array}$ & \\
\hline & M1 & General manager & & & B3 & M1 & Operation manager & Electric & 2500 \\
\hline S14 & M2 & Marketing director & manufacturer & 400 & & M2 & Procurement manager & $\begin{array}{l}\text { power } \\
\text { industry }\end{array}$ & \\
\hline S15 & M1 & Marketing director & Construction & 2500 & B1 & M1 & Procurement manager & Textile & 200 \\
\hline 315 & M2 & Customer director & industry & 2500 & & M2 & Operation manager & industry & \\
\hline & M1 & Senior market manager & & & B10 & M1 & Procurement manager & Medical & 8000 \\
\hline S16 & M2 & Marketing director & production & 2000 & & M2 & Operation director & $\begin{array}{l}\text { equipment } \\
\text { industry }\end{array}$ & \\
\hline
\end{tabular}

Table 1 Overview of firms and managers included in the empirical study (Co.=company, $S=$ supplier, $\mathrm{B}=$ buyer, $\mathrm{M}=$ manager, Emp.=\#employees)

\subsection{Data analysis approach}

The transcribed interviews were coded by the members of the research team. The analysis followed primarily a thematic approach (Braun \& Clarke, 2006), complemented by using open coding (Bryman \& Burgess, 1994). The underlying logic of the interview structure followed a 'funnel' approach that moves from the general/contextual level towards specifics (Patton, 2002). In phase one, with managers at supplier firms, this implied starting from the 'big picture' of attractiveness perceptions towards SM management practices, and then moving on to 
questions about the use of SM, with special regard to attractiveness implications, what worked well, and relevant aspects that have potential for future development. In phase two, with managers at buyer firms, the interviews started with general questions too, such as their roles and experiences/opinions on evaluating the attractiveness of suppliers, how SM influences these evaluations, if at all, and some focused questions based on the insights from phase one, such as what their opinions are about being highly social on social media and increased transparency enabled by social media. The 'funnel' logic has informed the data tabulation as well, starting from a wider perspective on organizational attractiveness, moving gradually towards specificities, including ways of how SM activities can enhance or decrease supplier attractiveness.

In both the supplier and buyer cases, interviewees were first asked about their role, responsibilities, the duration working for their company, a short introduction about the company, and the nature of buyer-supplier relationships of their firm and their industry (for example, duration of typical buyer-seller relationships in order to tackle market turbulence).

Within the scope of buyer-supplier relationship development, questions that were used for the interviews on the supplier side included - but were not limited to - (1) attractiveness considerations, mostly in relation to supplier attractiveness; (2) perceptions regarding different SM practices relevant to a buyer-supplier relational context; (3) reasons why the interviewee's firm uses SM and strategic considerations where this was applicable; (4) the role of SM in enhancing attractiveness, and (5) potential unintended effects of SM management. In phase two, among other questions, buyers were asked about, (1) how they select and evaluate suppliers; (2) how the SM of the supplier influences the supplier's attractiveness, if at all; (3) how characteristic it is to take the SM activities of the supplier into consideration when evaluating it; (4) in cases where the SM activities of the supplier are considered, whether it is normally taken into consideration at the selection and/or at later stages of the relationship and to what extent it is considered important; (5) which further factors they consider when evaluating supplier attractiveness; (6) how the supplier's SM presence influences how the buyer-supplier relationship evolves, if at all; (7) any cases where the supplier's SM discouraged it from purchasing from it; (8) reputational, trust-related, unintended/unanticipated/controversial effects of the supplier's SM usage and its impact on the supplier's attractiveness; (9) discussion of specific supplier cases regarding SM activities, and (10) perceptions and opinions about the right level of SM engagement, and increased transparency through SM. 
Some codes emerged beyond the initial template (that included, for example, trust-related and reputational SM effects on supplier attractiveness); incorporating elements of open coding allowed us to go beyond the initial pre-defined thematic coding. The coding procedure was supported by the NVivo 12 software to create parent- and child nodes, word frequencies, and word clouds that supported the discussions in the co-author team about data tabulation. No significant modifications to the coding structure were introduced after the analysis of the first 25 supplier interviews as well as after the $16^{\text {th }}$ of the buyer interviews in the sample; this suggests that theoretical saturation (Miles \& Huberman, 1994) had been reached, i.e. it is likely that analyzing additional transcripts would not have led to further substantial insights. The interview pairs conducted within the same companies were checked against each other as part of the within-case analysis (Miles \& Huberman, 1994), and mostly only minor differences were observed in relation to described SM activities and buyer-supplier relationship management practices.

\section{Analysis and results}

4.1. The Supplier's perspective: Supporting supplier attractiveness by using social media SM has been a widely used tool for supporting supplier attractiveness across all the interviewed suppliers. However, managers characteristically felt pressured about getting better at managing $\mathrm{SM}$, especially compared to their B2C counterparts. For instance, a sense of lagging behind was prevalent: "we need to become better at social media management (...) business-toconsumer firms know more about social media than business-to-business firms like us" (S6_M2). Managers typically assigned increasing importance to SM, and in particular, the power of SM for differentiation from competitors has been well-recognized: "social media enables us to distinguish ourselves from our competitors and make our clients realize our innovation capabilities” (S2_M1). In this subsection, first, pros and cons of using SM in B2B contexts are explored, then mechanisms and processes as well as external factors are highlighted that appeared relevant from the suppliers' perspective related to managing their attractiveness with the help of SM.

The main advantages of using SM relevant for attractiveness appeared to be non-financial benefits such as reputational benefits, for example, through the creation of quality content on SM (S11_M1), as well as network-related benefits such as the creation of positive Word-ofMouth (S5_M1, S13_M2). Identified disadvantages included that there was no salient link 
between SM activities and income generation (S15_M2), especially in contrast to business-toconsumer settings: "social media can be used to increase sales volume in business-toconsumer contexts, but it is impossible to do so in our industry" (S14_M1). Increasing time pressure within business interactions has been an issue too (S2_M2), yet suppliers are able to cope: "we usually respond as soon as possible" (S4_M2).

Relevant mechanisms include various means by which SM supports the new client acquisition process (attractiveness in pre- and early stages of the buyer-supplier relationship), and further develops relationships with buyers, for instance, in more mature relationships (S10_M1; S15_M1 \& S15_M2; S3_M2). In building new relationships, SM does not seem to replace the personal contact in business-to-business contexts but can serve as an initial trigger: "I think the major advantage of social media is that we can attract targeted buyers and they are willing to keep in touch with us. This is different from what we call hard sell” (S11_M1). As this quote demonstrates, SM helps business-to-business targeting in reaching out to specific groups of buyers. At a market attractiveness level, SM appears to be relevant for client acquisition in international settings and "to gain a foothold in new industries" (S1_M2).

Suppliers tended to place emphasis on the relationship-nurturing capacity of SM. SM interactions are greatly embedded in other relational mechanisms: "social media helps with bonding once you had a lot offace-to-face interaction" (S10_M2); "sharing images and videos of industry events via social media helps to reconnect with clients” (S12_M2). Some suppliers use SM merely because their buyers do so and they feel the need to embark on it too: "if our buyers use social media, we have to use it" (S5_M2). Overall, enhancing the personal relationship with SM interactions appears to strengthen the business relationship and results in more continuity - suppliers are well-aware of the need to maintain this: "the key point is to keep posting good quality materials on a regular basis" (S10_M1).

Network mechanisms facilitated by SM include borrowing attractiveness from partners to become an even more attractive supplier. Existing buyers can indeed make suppliers more attractive in the eyes of new clients and thus some suppliers actively seek their help on SM: "they can become evangelists of [supplier firm] and its products" (S1_M1). Therefore, some suppliers rely on "key clients to help with social media presence” (S7_M1), especially when it comes to sharing favourable information about the supplier on SM: "we share information about successful collaborations (...) as exposure to potential clients” (S13_M1). There was, however, awareness of the limitations of the extent to which SM can help them: "even though 
social media helps to put the icing on the cake, (...) clients won't trust us only for our social media activities” (S8_M1).

Some interviewees felt uncomfortable about sharing unanticipated effects of their firm's SM usage or preferred talking about such cases in general terms without sharing whether their firm has been directly affected. Negative comments on SM were associated more with business-toconsumer contexts rather than buyer-seller interaction on SM (S13_M2), yet suppliers expressed concerns about potential negative effects of SM interactions for themselves (S12_M2). Eliminating negative comments from their SM seemed to be a way to control them at least to some extent: "Even if these things happened, negative comments will be deleted. We definitely don't want any negative input” (S4_M2). There was a tendency towards being cautious with what the supplier shares, so that they could maintain a lasting professional image: "There cannot be disputes or negative information... We need to be cautious about using social media as we don't want to generate any negative feedback" (S4_M1). Some suppliers had product recalls with a digital footprint on their SM that they felt somewhat uncomfortable with (S7_M1).

Some suppliers minimized potential unanticipated effects by reducing SM interactions to specific topics such as "technical discussions and research and development trends of academic issues related to our business" (S8_M2). In fact, being 'too social' on SM can be seen as a weakness as one of the interviewees explained this about a competitor: "They are an iconic company and they are very social, but this is a strength and weakness at the same time. Their clients comment more on social media [than ours do] and the comments are mostly positive, which is great. When they had some technical problems, however, and there was a delay in delivering to their customers, the number of complaints on social media arose. Such negativity can spread fast and it is surely not what they wanted to see on social media" (S6_M2).

External factors that influence mechanisms about how SM activities influence the supplier's attractiveness include the maturity of buyer-supplier relationships, because the targeting of potential buyers via SM showed different dynamics compared to reconnecting within more established relationships. Market turbulence appears as another underlying factor: SM interaction appeared less relevant in low turbulence markets, where buyer-seller relationships typically last for decades. Hot topics in the industry are characteristically external to the 
supplier and arose in the wider business environment but may affect their attractiveness depending on whether/how they integrate them into their SM activities: "[to appeal to clients] we create discussions about 'hot topics' on social media" (S16_M2, S3_M1) that "spreads through relevant networks" (S3_M1).

\subsection{The Buyer's perspective on supplier attractiveness and social media}

SM matters primarily in supplier pre-selection. It appears that SM influences the very early phases of buyer-supplier relationships (e.g. B4_M2, B6_M2, B7_M2, B9_M2) and less so at the more mature phases of the relationship: "social media has some impact on the process of selecting suppliers, because social media is actually a reflection of word-of-mouth. But we don't think it will affect the later stages (e.g. payment) of the exchange relationship, because all these stages are managed in accordance with our standard procedures” (B6_M2).

Albeit a limited impact, SM can strengthen the supplier's attractiveness: “The supplier's social media will have a certain impact on word-of-mouth communication, (...) companies that often appear in the social media have certain credibility" (B2_M1); "it [SM] is the icing on the cake” (B5_M2). Besides, SM presence increases familiarity with the supplier: “...sometimes we read the information [on SM]. Honestly, continually posting information and news on social media is better than doing nothing, as this can increase familiarity. Although we have been very familiar with our suppliers" (B5_M1). Some buyers consider SM as a necessary but not sufficient tool: "People will have a positive image about the company that manages their social media well. (...) Reputation on social media is not enough for a company to become our supplier: the company needs to be professional" (B7_M2); "Nowadays, it is impossible for suppliers to not to engage with social media. But I don't think that companies in our industry need to do a lot of social media” (B2_M1). Some buyers do not assign much importance to whether the supplier has SM presence: “We don't really have a supplier that is bad at social media activities. The worst situation is when a supplier does not set up an account on social media. Yet we are still willing to build cooperation with those companies without social media accounts" (B8_M2).

Nonetheless, not having any SM presence at all can create an unfavourable impression: "Some suppliers do not spend money on advertisements on social media, which I think is too out of date. Currently, more and more people are using social media, but some suppliers are not. This could be a problem" (B8_M1); "If a supplier doesn't even have Weibo or WeChat, it 
means the company is lagging in information management, and the degree of socialization is very low. This also means the company doesn't care about their reputation” (B5_M2). Buyers who consider the SM activities of the supplier, characteristically use it as background information when searching for new suppliers: "We will use social media to investigate some company background information. I don't think it plays another role” (B6_M1); "I think social media can provide basic background information in building relationships with suppliers. As time passed, we will collect more and more information. If we are not familiar with a supplier, we will search their information on the Internet" (B4_M2). The ease of search is appreciated from the buyer's perspective and so is the supplier's well-managed SM presence that contributes to this: "We have suppliers that are well-known on the Internet and have a good reputation on social media. Good suppliers can be easily found through the Internet, shortening the time it takes us to evaluate them" (B7_M1).

Conflicting views arose about the increased transparency through SM. There is no consensus among the interviewed buyers about the usefulness of the increased transparency that comes with SM presence. Some buyers believe that transparency improves relationships: "I think it's a good thing. Transparent operation is also helpful to the whole industry. It will be difficult to do business in the industry where black box operation exists" (B1_M2); "I think increased transparency can be a good thing. And the transparency will increase over time in business cooperation" (B8_M1). Some believe it depends on the context: "I don't think it's a good thing or a bad thing. It's normal. Whether it is a good thing depends on the context? Sometimes you need to know who your supplier is contacting with. Sometimes you don't want to know that" (B2_M2). Others perceive transparency as disadvantageous: "this is definitely a bad thing" (B3_M2); “...social media has the value of transparency, which is not a good thing in our procurement process" (B10_M2), and worry about pricing agreements (i.e. information available on SM can lead to "price confusion" according to B5_M1). Increased network visibility is a concern to some buyers: "Why do we have to know whom our suppliers are connected to? I think it is a bad thing for our business" (B4_M1); "I think information transparency is a bad thing as the relationship between us and our suppliers will be known by others"(B9_M2).

Unmanaged negative feedback on the supplier's SM, however, can be especially discouraging: "if we learn that there is some problems with product quality or there is negative feedback on social media, it will influence how we see that supplier" (B3_M1); "social media will influence 
our selection of suppliers. At least we will look at whether they have negative news. (...) Of course, companies will try to control and delete negative feedback. If a supplier completely ignores such negative information or evaluation on social media, this means the company does not care about their reputation. Hence, we are unwilling to cooperate with such suppliers" (B1_M1). In fact, bad news travel fast - and even faster on SM: "I heard [on SM] that a supplier was involved in grey commercial bribery. This is absolutely forbidden in our company, so we terminated our cooperation with them". While prompt relationship termination following negative news on SM is not unprecedented, reputational damage can be long-lasting (B10_M1).

Some buyers are afraid of themselves or their suppliers being attacked by competitors on SM: "You can see whom your supplier is talking to online, what they're replying, or what they've been doing lately, but it's a double-edged sword. The concern is that sometimes your competitor will attack you online, even if there's a small problem, or no problem at all" (B5_M1). It appears that these concerns are not unreasonable: “[Supplier]'s news on social media has almost become the sourcing news of industry associations (...) There were voices on social media saying that [Supplier]'s legendary background had fallen, so it was under great risks. However, this proved to be a rumour (...) This example is quite memorable because we have had a cooperative relationship with [Supplier], and (...) [that time we had] a temporary suspension the projects with them" (B2_M1). This collaboration has later been reinstated. Besides competitors' attacks, for relationship termination or temporary suspension, it may well be enough that the supplier complains on SM: “...one of our suppliers has complained online because of overdue payment. This triggered some negative comments. Then we needed to temporarily suspend the cooperation with them" (B3_M1).

Being 'too social' on SM can reduce supplier attractiveness. While suppliers having some SM presence was perceived as normal and even sometimes expected by the buyers, over-doing SM activities appeared unnecessary, and in some cases repulsive. Some buyers, for instance B4_M2, expressed indifference over the excessive SM activities of some of their suppliers: "even though they do a lot on social media, it doesn't make any big difference to us". Some other buyers, such as B1_M2, were somewhat concerned about suppliers' spending on SM that does not generate reasonable return on investment: "When more information is published and the information is shared by more people, more and more people will be informed. This makes 
the company more famous. But this comes with a cost. I've heard before that some suppliers are investing a lot of effort into managing their social media. But it has no impact on sales".

SM creates a personification of the company that appeared in buyers' descriptions when talking about suppliers that are highly active on SM. The notion of 'too social' seems to vary across industries. Nonetheless, being 'too social' on SM creates an unfavourable impression about the supplier: "It's not normal for a supplier to be too social. Just like the boss of a company, he goes out for socialization, makes speeches or participates in various social parties every day, but he does not improve skills or manage his own company well, the company will collapse sooner or later without a good product” (B2_M2). In this case, the excessive SM activities of the supplier made the buyer question how much the supplier cares about diligent, high quality work, and thus how stable the firm is in the long run given that their priorities are elsewhere. Another buyer envisioned operational difficulties: "It is difficult for a company to operate well if the company pay much attention on social media and the manager always attends social occasions but does not pay attention to the management and operation of the company" (B3_M2). Buyers acknowledged that intense SM activities can raise the awareness and appeal of the supplier but there were concerns that with SM activities this positive impact can vanish or turn into a bad reputation. As one of the buyers pointed out: "There is an old saying goes like this: 'Not only can water float your boat, it can sink it too'. (...) From what I understand, being too social means that a company relies too much on social media and is keen on hyped reputation. They will put a lot of effort on attracting and operating fan groups and focus on their characteristics rather than the nature of the product. So, I think this can lead to some problems”(B10_M2).

Pertaining to mechanisms through which SM influences attractiveness, buyers typically expressed passivity about their suppliers' SM activities (e.g. B1_M1, B2_M1, B9_M1): "I only give "likes" for my family, but not for my suppliers" (B1_M1), but may still use SM as a monitoring device: "I never give likes to them [suppliers]. I will only look at the WeChat post or articles, but never give likes. But sometimes I collect articles, which I think are good and useful" (B1_M2). Suppliers' SM interaction efforts are sometimes largely neglected: "I remember that I will receive likes from our suppliers on social media. But I think that it is just a kind of entertainment during our spare time. And it will not have impact on us" (B5_M2). Interestingly, one of the buyers highlighted the perceived 'magnifying glass' mechanism of SM. SM has the capacity to make positive traits of the supplier appear in an even more 
favourable light, but can worsen how their shortcomings are evaluated: “...companies can increase the exposure and effectiveness of advertising to enhance their reputation and magnify their power of social communication. But social media won't play a decisive role, as it only functions as a magnifying glass. If things at the core level are not good, social media will spread the bad news to the world. If the supplier works well, then the word-of-mouth on social media will be good" (B3_M1).

Some important external factors apply that can influence buyers' perceptions of how SM activities influence supplier attractiveness and the sort of preferred forms of SM interaction. For example, there are industry characteristics, such as closeness of relationships and level of turbulence. A buyer in a low turbulence environment with mostly long-term, stable suppliers explained that they did not experience anything unusual or unanticipated on SM but partly this is due to the fact that, "We are in a relatively closed industry" (B3_M2). Another buyer explained preferences pertaining to the geographical location of suppliers: "It is a relatively traditional industry, and the network circle in our textile industry is not big. We usually cooperate with some fix partners located in the area of Nantong. To be honest, we are not experienced on social media activities" (B1_M1). Buyers demonstrated some awareness of international-cultural differences pertaining to SM practices too. For instance, one of the interviewed buyers noted that, "WeChat is not used in foreign countries, and even some countries don't like voice type of social media” (B3_M2).

The results of the focus group were aligned with the in-depth interviews. Ease of search and good integration across different SM sites and the corporate website as well as regular updates on the supplier's SM were preferred: “it doesn't look good if they started some social media activities some time ago and then let them die off. It's like arriving at an abandoned factory site”, but SM expectations were limited: "nobody expects shiny Coca-Cola-like social media in $B 2 B$ ". It arose, however, that negative comments that spread on SM in a B2C context, regarding a car rental service, later influenced B2B decision making regarding potential suppliers.

\subsection{Comparing the Buyer's and the Supplier's perspective on SM's role in managing supplier attractiveness}

Suppliers reported considerable pressure to improve their SM presence, especially compared to their B2C counterparts. Buyers, by contrast, assigned even less importance to the suppliers' 
SM activities throughout the exchange relationship. In fact, concerns were expressed about when suppliers appeared to be 'too social' on SM. Another striking difference was that suppliers seemed to focus their SM efforts on nurturing buyer-supplier relationships, whereas the buyers who engage in SM activities, use information gained through SM primarily during the supplier pre-selection and early stages of the relationship. Furthermore, suppliers appeared to be pleased with the increased transparency SM offered, as this facilitated the identification of specific contact persons: "I actually see suppliers sending us information on SM and asking who is responsible for our purchasing plan, procurement and so on” (B1_M1). Buyers, however, expressed mixed feelings towards increased transparency that comes with SM, partly because they intend to withhold purchasing-related communications away from SM interfaces. A common trait between the buyers' perceptions and the suppliers' SM practices was that both sides paid attention to the management of negative comments and reactions on SM. This is indeed important because unmanaged negative comments on the supplier's SM deemed to make the supplier less attractive in the eyes of the buyers. While SM was the "icing on the cake' for both sides, negativity on the supplier's SM caused its attractiveness to deteriorate. There were some minor differences across various industries (both on the buyer and supplier side) on how important SM is for supplier attractiveness. SM proved to be considerably less important in traditional industries such as the textile industry, as well as the electric power industries that are normally characterized by close business relationships and low environmental turbulence. Managers from the same companies provided similar descriptions about SM and supplier attractiveness. Some attitudinal differences towards SM between managers applied.

\section{Discussion and implications}

This section reflects on how the findings can inform ongoing academic discussions on the role of SM in supplier attractiveness. As part of this, with future research directions in mind, a set of propositions is offered on how SM can influence supplier attractiveness and thus competitive advantage. Three key themes are identified: 'being too social' on SM, increased transparency through SM, and misalignment between suppliers' assumptions and buyers' practices pertaining to the purposes for which suppliers' SM is utilized. As for managerial implications, we then consolidate several SM management aspects, which emerged from the interviews, and categorize them relevant to business growth and supply chain development. 
First, we found that in B2B contexts, suppliers experience an increasing pressure to close the digital gap between them with their B2C counterparts (also see McKinsey, 2016), including implementing B2C firms' high intensity SM practices. The dynamic SM approach taken to several B2C companies, however, does not appear preferable by the buyers. While having some well-managed and structured SM presence was commended by the buyers, being 'too social' on SM, according to the standards of the industry, was perceived as risky. Suppliers that are highly active on SM are more prone to potential negativity that spreads through social networks. Also, suppliers with highly intense SM activities were perceived as having their priorities on socializing rather than improving the quality of their work. Thus, for B2B contexts, we propose an inverse U-shaped baseline relationship between the intensity of the supplier's SM activities and the contribution of SM to the supplier's attractiveness. The turning point from where increasing SM activities is perceived as a waste of resources or even as a reputational risk may vary across industries. Furthermore, if the buyer does not attach importance to their own firm's SM, it is likely that the SM-related expectations towards suppliers are even lower. Overall, suppliers should avoid 'trying too hard'; having some social media presence increases supplier attractiveness but being 'too social' on social media does not seem to further increase supplier attractiveness. This provides a new illustrative case, specific to SM, for the report of Daub (2007) on how, why and in which contexts companies try to avoid appearing to be 'too social'.

P1: In a B2B context the level of SM intensity shows a $U$-shaped relationship with supplier attractiveness.

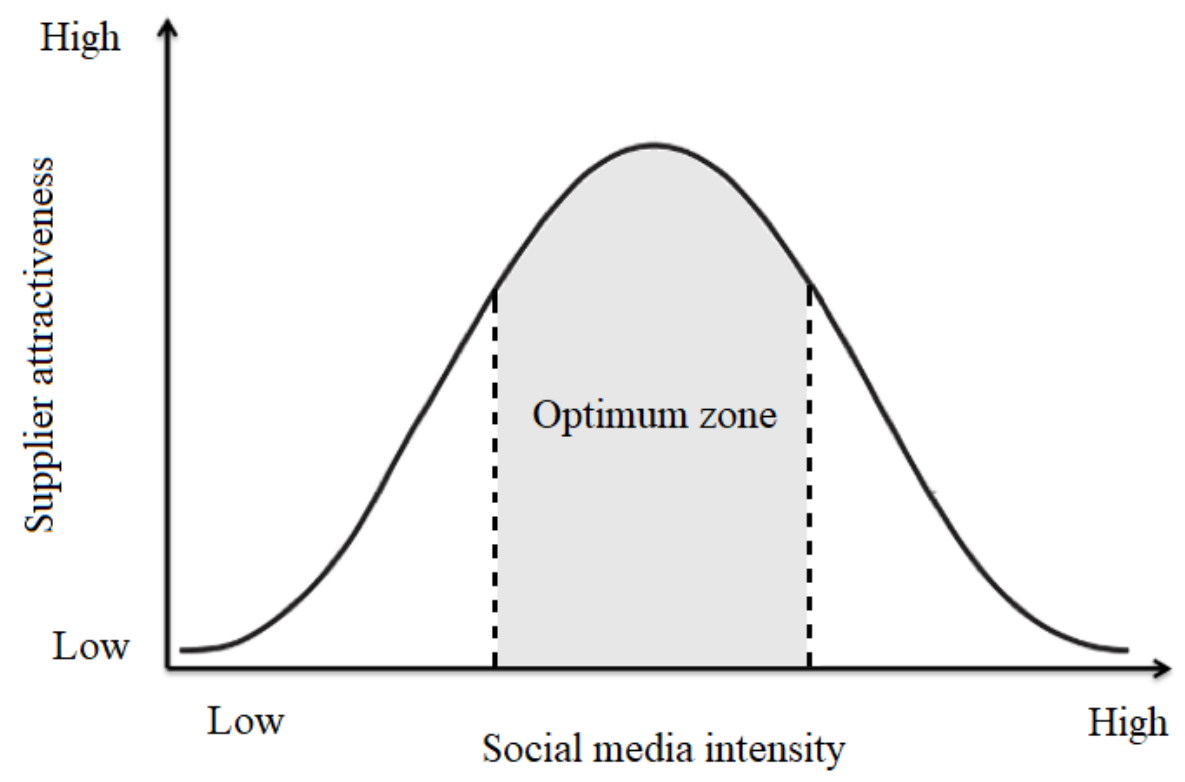


Figure 1 The U-shaped relationship between SM intensity and supplier attractiveness

Secondly, the increased transparency pertaining to daily operations, events, and the connectedness of companies through SM appears controversial. Empirical evidence suggests that managers on the supplier side seek to identify points of contacts via SM when developing buyer-seller relationships. SM proved to be helpful in achieving this endeavour. Some buyers confirmed that they have been contacted by suppliers via SM and that in some cases (e.g. personal WeChat communications) SM may have some positive impact on the relationship with the supplier. There was, however, a sense of protectiveness from the buyers towards information that flows on SM networks. In particular, buyers intend to keep supplier selection criteria, bidding, and pricing information away from SM communications. Such enquires from suppliers can trigger aversion. Some buyers are concerned about the visibility of their suppliers' connections too. The increased transparency of the network through SM responds to some challenges of multi-level networks (Payne et al., 2011), such as the cohesion between inter-personal and inter-organizational networks. The controversial effect of increasing transparency in supply chains is highlighted by Braziotis and Tannock (2011). Lamming et al. (2006) discussed opaque, translucent, and transparent ways of information-sharing between suppliers and buyers and that social and technology-led drivers increase transparency, without yet incorporating the effects of SM. Our study extends these discussions on transparency to an SM context and proposes that besides relational benefits, the increased transparency on SM creates potential tensions in managing supplier attractiveness.

P2: The increased transparency through social media triggers controversies; it is characteristically welcomed by suppliers but less so among buyers and can influence supplier attractiveness either way.

Suppliers emphasized SM's potential to maintain and develop relationships with buyers. SM was characteristically seen as a platform for keeping in touch, especially following industry events and other in-person interactions with buyers. Some suppliers mentioned the role of SM in supplier pre-selection but there appears to be a tendency to pay more attention to SM activities with the aim of strengthening existing relationships with buyers instead of making supplier acquisition easier. In contrast, among buyers, there appears to be a consensus that the supplier's SM is primarily utilized as part of the general background check in supplier preselection. Easy navigation across SM sites, the corporate website, as well as structured and 
regularly updated information shared on SM, were appreciated and contributed to building an overall favourable impression about the supplier.

Although for later stages of the relationship the presence of SM activities was acknowledged, it was largely neglected by the buyers. Part of the reason may be that the socialization between buyers and suppliers is often frowned upon (Cousins et al., 2006). An exception to neglecting the suppliers' SM activities was the potential emergence of bad news and negative comments. Suppliers appear to be well-aware that they should try to stop the spread of negativity on SM and that negative comments should be managed in a timely manner. The influence of negative comments in B2B SM is not unknown in the literature, for instance, it is mentioned by Michaelidou et al. (2011).

P3: The supplier's social media is monitored by buyers typically during the supplier preselection process and plays a less important role at later stages of the exchange relationship.

With the focus on managerial implications, Figure 2 summarizes the key results about SM management relevant to supplier attractiveness. The classification proposed assists in identifying the connections between attractiveness drivers and management impact areas in the form of a set of specific results. Practitioners could use the proposed framework to identify the expected results from SM management that are relevant to supplier attractiveness and to identify areas their organizations need to invest in to effectively manage SM activities and increase attractiveness. The classification can assist in the strategic management of SM and the anticipated organizations' results for their appeal to the customer. Based on our analysis, SM activities can have different results to SM management that are relevant to supplier attractiveness. We distinguish between results that relate to outcomes for the strategic growth of the individual business, i.e. Business Growth, and those that refer to Supply Chain Development. 
Effective Social Media Management

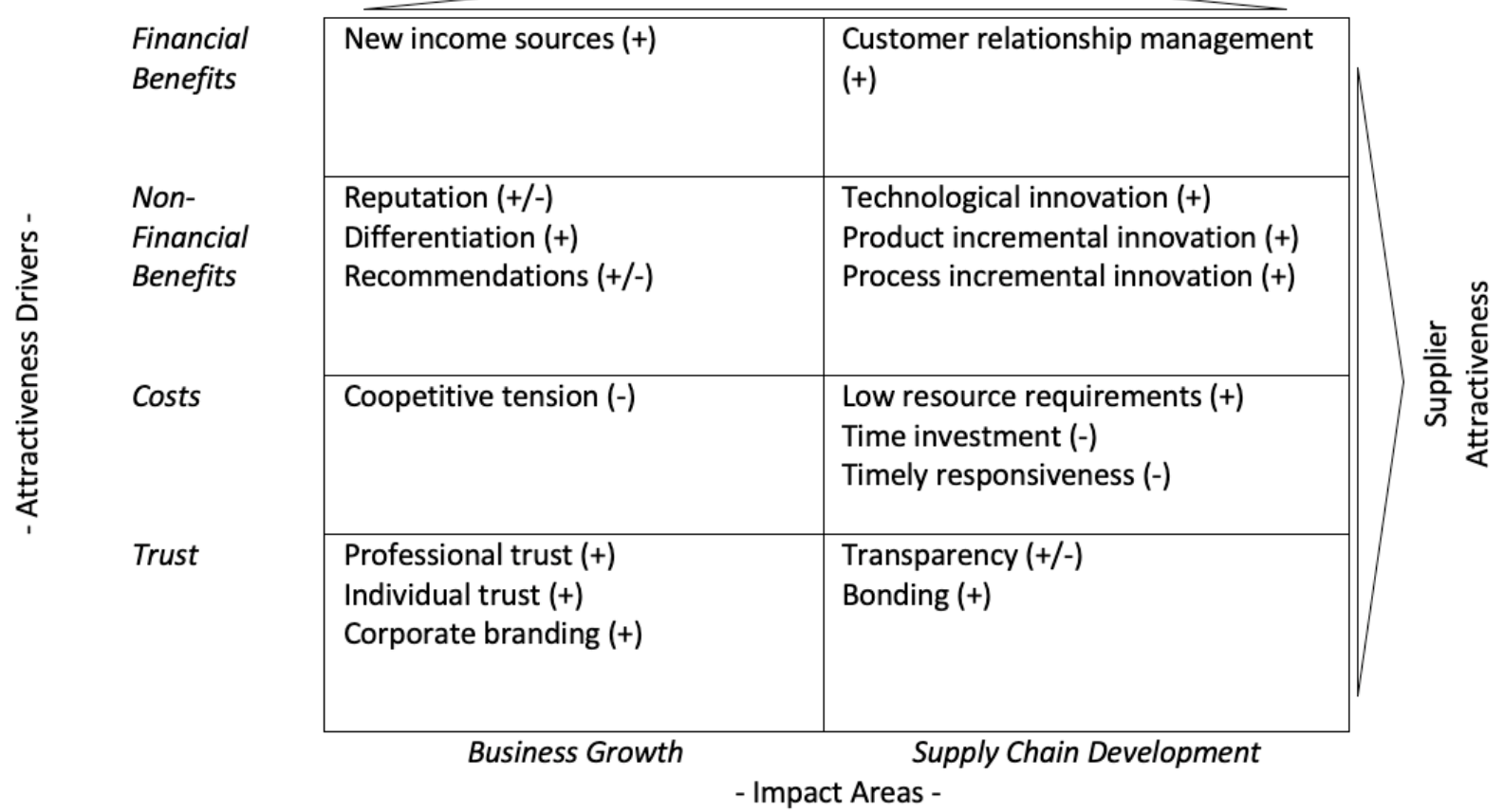

Figure 2 Strategic SM management considerations for supplier attractiveness through the impact areas of Business Growth and Supply Chain Development

In terms of financial benefits, new income sources emerged as the main positive result for business growth. There was strong evidence that SM activities lead to increased attractiveness, as they encourage purchases for existing and new customers. Customer Relationship Management (CRM) was the main positive result relevant to operations and supply chain development. Supplier-buyer relationship management is further facilitated by client data from $\mathrm{SM}$; one of the aims of CRM is to maximize value for the relationship.

In terms of non-financial benefits, differentiation, reputation, and recommendations appeared as the key results for business growth opportunities. SM can assist in distinguishing a company from its competitors and make buyers more aware of the supplier's innovation capabilities this can be increasingly relevant for supplier selection. Differentiation through SM is especially relevant for building competitive advantage. Generating recommendations on SM was identified as a long-term and important process to building reputation. Feedback collected on SM assists in improving technological innovation.

Regarding costs, coopetitive tension on SM (due to the combination of cooperation and competition) was the main negative result for business growth. Effective SM management results in both enhanced professional and individual trust, and in improving corporate branding. For operations and supply chain development, it results in greater bonding. It allows the 
establishment of channels for better and frequent communication with clients and sharing information about products. The integration of SM channels results in an effective shortening of the communication processes.

\section{Conclusions}

By means of a case study methodology, our study captured both the supplier and buyer side and explored the role of SM in managing supplier attractiveness in B2B contexts. As per our research question, we aimed to understand how suppliers' SM activities influence their attractiveness. A set of clear findings have emerged from the analysis in the form of propositions that highlight different perspectives on the implications of engaging in SM for suppliers and buyers. The study revealed that 'SM intensity' needs to be carefully managed to ensure appropriate levels of attractiveness, namely avoid the state of being perceived by the buyers as being 'too social' on SM. In addition, our study revealed that while increased transparency through SM is positively received by suppliers, it is not always positively perceived by buyers and has variable impacts on supplier attractiveness. Our study also revealed that suppliers' SM engagement is more influential in their pre-selection phase. Finally, the study identified the specific results from the interplay between attractiveness drivers and management impact areas, which are essential for organisations to assess the impact of strategic SM management on competitive advantage.

Cultural differences as limitations to generalizability are acknowledged. For instance, there is a surveillance function of SM to monitor local governments and officials in China (Qin et al., 2017), which has limited importance to the management of buyer-supplier relationships. However, it may indirectly encourage a more cautious approach to the type of content shared on SM. Besides the quantitative testing of the outlined propositions, future research should further investigate the time perspective of SM activities regarding supplier attractiveness by taking a longitudinal approach. This would enable the study of various 'stages' of how supplier attractiveness evolves over time and how SM's influence varies over time.

\section{Acknowledgement}

This research was supported by National Natural Science Foundation of China (Grant No. 71972112) and Zhejiang Natural Science Foundation (LQ17G020009). 


\section{References}

Agnihotri, R., Dingus, R., Hu, M.Y. and Krush, M.T., 2016, "Social media: Influencing customer satisfaction in B2B sales”, Industrial Marketing Management, 53, pp. 172-180.

Alfaro, J.A. and Tribó, J.A., 2003, “Operations manager turnover and inventory fluctuations”, International Journal of Production Economics, 81, pp. 51-58.

Aminoff, A. and Tanskanen, K., 2013, "Exploration of congruence in perceptions of buyersupplier attraction: A dyadic multiple case study", Journal of Purchasing and Supply Management, 19(3), pp. 165-184.

Aral, S., Dellarocas, C. and Godes, D., 2013, "Introduction to the special issue - Social media and business transformation: a framework for research", Information Systems Research, 24(1), pp. 3-13.

Azadegan, A. and Dooley, K.J., 2010, "Supplier innovativeness, organizational learning styles and manufacturer performance: An empirical assessment", Journal of Operations Management, 28(6), pp. 488-505.

Barney, J., 1991, "Firm resources and sustained competitive advantage", Journal of Management, 17(1), pp. 99-120.

Bemelmans, J., Voordijk, H., Vos, B. and Dewulf, G., 2015, "Antecedents and benefits of obtaining preferred customer status: Experiences from the Dutch construction industry", International Journal of Operations \& Production Management, 35(2), pp. 178-200.

Bollen, J., Mao, H. and Zeng X., 2011, "Twitter mood predicts the stock market", Journal of Computer Science, 2(1), pp. 1-8.

Braun, V. and Clarke, V., 2006, "Using thematic analysis in psychology", Qualitative Research in Psychology, 3(2), pp. 77-101.

Braziotis, C. and Tannock, J., 2011, "Building the extended enterprise: key collaboration factors", International Journal of Logistics Management, 22(3), pp. 349-372.

Bryman, A. and Burgess, R.G., 1994, Developments in qualitative data analysis: an introduction. Analyzing Qualitative Data, pp. 1-17.

Chae, B.K., 2015, "Insights from hashtag \#supplychain and Twitter analytics: Considering Twitter and Twitter data for supply chain practice and research", International Journal of Production Economics, 165, pp. 247-259.

Cousins, P.D., Handfield, R.B., Lawson, B. and Petersen, K.J., 2006. "Creating supply chain relational capital: the impact of formal and informal socialization processes". Journal of Operations Management, 24(6), pp.851-863.

Chen, S.Z., 2012, "Social media: An unmissable opportunity for Chinese enterprises", Modern Economic Information, 6, pp. 117-118.

Cheng, T.C.E. and Musaphir, H., 1996, "Theory and practice of manufacturing strategy", International Journal of Production Research, 34(5), pp. 1243-1259. 
Cui, R., Gallino, S., Moreno, A. and Zhang, D.J., 2018, “The operational value of social media information", Production and Operations Management, 27(10), pp. 1749-1769.

Daub, C.H., 2007, "Assessing the quality of sustainability reporting: An alternative methodological approach", Journal of Cleaner Production, 15(1), pp. 75-85.

Dubois, A. and Gadde, L.E., 2002, "Systematic combining: an abductive approach to case research", Journal of Business Research, 55(7), pp. 553-560.

Dickson, P.R. and Ginter, J.L., 1987, "Market Segmentation, Product Differentiation, and Marketing Strategy." Journal of Marketing, 51(2), pp. 1-10.

Ellegaard, C. and Ritter, T., 2007, "Attractiveness in business markets: Conceptualization and propositions", Industrial Purchasing White Paper, pp. 1-10.

Fiocca, R., 1982, “Account portfolio analysis for strategy development”, Industrial Marketing Management, 11(1), pp. 53-62.

Gosling, J., Purvis, L. and Naim, M.M., 2010, "Supply chain flexibility as a determinant of supplier selection”, International Journal of Production Economics, 128(1), pp. 11-21.

Guo, H., Xu, H., Tang, C., Liu-Thompkins, Y., Guo, Z. and Dong, B., 2018, “Comparing the impact of different marketing capabilities: Empirical evidence from B2B firms in China", Journal of Business Research, 93, pp. 79-89.

Hald, K.S., Cordón, C. and Vollmann, T.E., 2009, “Towards an understanding of attraction in buyer-supplier relationships", Industrial Marketing Management, 38(8), 960-970.

Kaplan, A.M. and Haenlein, M., 2010, "Users of the world, unite! The challenges and opportunities of Social Media", Business Horizons, 53(1), pp. 59-68.

Karlsson, C., Taylor, M. and Taylor, A., 2010, "Integrating new technology in established organizations: A mapping of integration mechanisms", International Journal of Operations \& Production Management, 30(7), pp. 672-699.

Kauremaa, J., Småros, J. and Holmström, J., 2009, "Patterns of vendor-managed inventory: findings from a multiple-case study", International Journal of Operations \& Production Management, 29(11), pp. 1109-1139.

Lacoste, S., 2016, "Perspectives on social media ant its use by key account managers", Industrial Marketing Management, 54, pp. 33-43.

Lam, H.K., Yeung, A.C. and Cheng, T.E., 2016, “The impact of firms' social media initiatives on operational efficiency and innovativeness", Journal of Operations Management, 47, pp. 2843.

Lamming, R.C., Caldwell, N.D., Harrison, D.A. and Phillips, W., 2001, "Transparency in supply relationships: concept and practice”, Journal of Supply Chain Management, 37(3), pp.410 .

Leonardi, P.M., 2014, "Social media, knowledge sharing, and innovation: Toward a theory of communication visibility”, Information Systems Research, 25(4), pp. 796-816. 
Levina, N. and Arriaga, M., 2014, "Distinction and status production on user-generated content platforms: Using Bourdieu's theory of cultural production to understand social dynamics in online fields", Information Systems Research, 25(3), pp. 468-488.

Luo, X., Zhang, J. and Duan, W., 2013, "Social media and firm equity value", Information Systems Research, 24(1), pp. 146-163.

Luzzini, D., Caniato, F., Ronchi, S. and Spina, G., 2012, “A transaction costs approach to purchasing portfolio management", International Journal of Operations \& Production Management, 32(9), pp. 1015-1042.

Makkonen, H., Vuori, M. and Puranen, M., 2016, "Buyer attractiveness as a catalyst for buyersupplier relationship development”, Industrial Marketing Management, 55, pp. 156-168.

Malhotra, A., Melville, N.P. and Watson, R.T., 2013, "Spurring impactful research on information systems for environmental sustainability", MIS Quarterly, 37(4), pp. 1265-1274.

Mani, V. and Gunasekaran, A., 2018, "Four forces of supply chain social sustainability adoption in emerging economies", International Journal of Production Economics, 199, pp. 150-161.

Matthews, R.L., MacCarthy, B.L. and Braziotis, C., 2017, "Organisational learning in SMEs: a process improvement perspective", International Journal of Operations \& Production Management, 37(7), pp. 970-1006.

McKinsey \& Partners, 2012, There are 300 million social media users in China! https://www.mckinsey.com/business-functions/marketing-and-sales/our-

insights/understanding-social-media-in-china

McKinsey \& Partners, 2016, Measuring B2B's digital gap. https://www.mckinsey.com/business-functions/marketing-and-sales/our-insights/measuringb2bs-digital-gap?cid=eml-web

Michaelidou, N., Siamagka, N.T. and Christodoulides, G., 2011, "Usage, barriers and measurement of social media marketing: An exploratory investigation of small and medium B2B brands", Industrial Marketing Management, 40(7), pp. 1153-1159.

Miles, M.B. and Huberman, M., 1994, Qualitative data analysis: An expanded sourcebook, Sage: New York.

Mitrega, M., Forkmann, S., Zaefarian, G. and Henneberg, C.S., 2017, "Networking capability in supplier relationships and its impact on product innovation and firm performance", International Journal of Operations \& Production Management, 37(5), pp. 577-606.

Mortensen, M.H., 2012, "Understanding attractiveness in business relationships - A complete literature review”, Industrial Marketing Management, 41(8), pp. 1206-1218.

Olsen, R.F. and Ellram, L.M., 1997, “A portfolio approach to supplier relationships”, Industrial Marketing Management, 26(2), pp. 101-113.

Ollus, M., Jansson, K., Karvonen, I., Uoti, M. and Riikonen, H., 2011, "Supporting collaborative project management”, Production Planning \& Control, 22(5/6), pp. 538-553. 
Osiro, L., Lima-Junior, F.R. and Carpinetti, L.C.R., 2014, "A fuzzy logic approach to supplier evaluation for development", International Journal of Production Economics, 153, pp. 95-112.

Patton, M.Q., 2002, "Two decades of developments in qualitative inquiry: A personal, experiential perspective", Qualitative Social Work, 1(3), pp. 261-283.

Payne, G.T., Moore, C.B., Griffis, S.E. and Autry, C.W. (2011), "Multilevel challenges and opportunities in social capital research", Journal of Management, 37(2), pp. 491-520.

Porter, M.E. (1985), Competitive Advantage: Creating and Sustaining Superior Performance, The Free Press, New York.

Quinton, S. and Wilson, D., 2016, "Tensions and ties in social media networks: Towards a model of understanding business relationship development and business performance enhancement through the use of LinkedIn", Industrial Marketing Management, 54, pp. 15-24.

Rapp, A., Beitelspacher, L.S., Grewal, D. and Hughes, D.E., 2013, "Understanding social media effects across seller, retailer, and consumer interactions", Journal of the Academy of Marketing Science, 41(5), pp. 547-566.

Ramsay, J., Wagner, B. and Kelly, S., 2013, "Purchase offering quality: The effects of buyer behaviour on organizational supplying behaviour", International Journal of Operations \& Production Management, 33(10), pp. 1260-1282.

Roberts, D.L. and Piller, F.T., 2016, "Finding the right role for social media in innovation", MIT Sloan Management Review, 57(3), pp. 41-49.

Sashi, C.M., 2012, "Customer engagement, buyer-seller relationships, and social media", Management Decision, 50(2), pp. 253-272.

Sharma, N. and Patterson, P.G., 2000, "Switching costs, alternative attractiveness and experience as moderators of relationship commitment in professional, consumer services", International Journal of Service Industry Management, 11(5), pp. 470-490.

Tanskanen, K. and Aminoff, A., 2015, "Buyer and supplier attractiveness in a strategic relationship - A dyadic multiple-case study", Industrial Marketing Management, 50, pp. 128141.

Thomas-Seale, L.E.J., Kirkman-Brown, J.C., Attallah, M.M., Espino, D.M. and Shepherd, D.E.T., 2018, "The barriers to the progression of additive manufacture: perspectives from UK industry", International Journal of Production Economics, 198, pp. 104-118.

Tóth, Z., Thiesbrummel, C., Henneberg, S.C. and Naudé, P., 2015, "Understanding configurations of relational attractiveness of the customer firm using fuzzy set QCA", Journal of Business Research, 68(3), pp. 723-734.

Trainor, K.J., Andzulis, J.M., Rapp, A. and Agnihotri, R. 2014, "Social media technology usage and customer relationship performance: A capabilities-based examination of social CRM”, Journal of Business Research, 67(6), pp. 1201-1208.

Zarrinpoor, N., 2018, “An Exploration of Evolutionary Algorithms for a Bi-Objective Competitive Facility Location Problem in Congested Systems", International Journal of Supply and Operations Management, 5(3), pp. 266-282. 
Zhao, Y. and Wang, G., 2011, "The impact of relation-specific investment on channel relationship performance: evidence from China", Journal of Strategic Marketing, 19(1), pp. $57-71$.

Zhou, L. and Wang, T., 2014, "Social media: A new vehicle for city marketing in China", Cities, 37, pp. 27-32. 